\title{
Suppression of Fatty Acid Synthase by Dietary Polyunsaturated Fatty Acids is Mediated by Fat itself, not by Peroxidative Mechanism
}

\author{
Hyekyeong Kim, Sungwon Choi, Hae-Jeung Lee, Joo-Hee Lee ${ }^{\dagger}$ and Haymie Choi* \\ Department of Food and Nutrition, Seoul National University, Seoul 151-742, Korea \\ ${ }^{\dagger}$ Department of Food and Nutrition, Kyungsang National University, Jinju 660-701, Korea
}

Received 8 October 2002, Accepted 11 December 2002

\begin{abstract}
This study examined the effect of dietary polyunsaturated fatty acids (PUFA) that were supplemented with vitamin $E$ on lipid peroxidation, glutathione-dependent detoxifying enzyme system activity, and lipogenic fatty acid synthase (FAS) expression in rat liver. Male Sprague-Dawley rats were fed semipurified diets containing either $1 \%(\mathrm{w} / \mathrm{w})$ corn oil or $10 \%$ each of beef tallow, corn oil, perilla oil, and fish oil for $4 \mathrm{wk}$. Alpha-tocopherol was supplemented in perilla oil $(0.015 \%)$ and fish oil $(0.019 \%)$. Hepatic thiobarbituric acid reactive substances, an estimate of lipid peroxidation, were not significantly different among the dietary groups. The glutathione peroxidase, glutathione reductase, and glutathione S-transferase activities were all elevated by the polyunsaturated fats, especially fish oil. The activity of FAS was reduced in the polyunsaturated fat-fed groups in the order of fish oil, perilla oil, and corn oil. The mRNA contents decreased in rats that were fed the $10 \%$ fat diets, particularly polyunsaturated fats, compared with the rats that were fed the $1 \%$ corn oil diet. Similarly, the inhibitory effect was the greatest in fish oil. These results suggest that lipid peroxidation can be minimized by vitamin E; PUFA in itself has a suppressive effect on lipogenic enzyme.
\end{abstract}

Keywords: Fatty acid synthase, Glutathione peroxidase, Lipid peroxidation, Polyunsaturated fatty acids, Vitamin E

\section{Introduction}

Several studies demonstrated that dietary polyunsaturated fatty acids (PUFA) suppress hepatic lipogenesis relative to saturated and monounsaturated fatty acids (Clarke et al.,

*To whom correspondence should be addressed.

Tel: 82-2-880-8767; Fax: 82-02-877-1031

E-mail: choihm@snu.ac.kr
1977; Blake and Clarke, 1990). The suppression is accompanied by inhibiting the hepatic synthesis of lipogenic enzyme protein, notably fatty acid synthase (FAS) and acetylCoA carboxylase (Clarke and Abraham, 1992).

However, the mechanisms by which PUFA suppress lipogenesis are not completely understood. Studies with eicosa-5,8,11,14-tetraynoic acid (ETYA), an inhibitor of $\Delta^{6}$ desaturase and arachidonic acid metabolism, suggest that the suppressive effect of nutritionally-essential C18 PUFA, linoleic acid (LA), and $\alpha$-linolenic acid ( $\alpha$-LNA) is mediated by their conversion to C20 PUFA (Clarke and Clarke, 1982). According to the hypothesis of Jump and Clarke (1996), these PUFA interact directly with protein factors that bind to the specific regulatory cis-acting PUFA responsive element in the promoter region in order to govern gene transcription. On the other hand, recent studies suggested that the inhibitory effect of PUFA is linked to a cytotoxic effect, due to the peroxidative mechanism (Mikkelson et al., 1993; Foretz et al., 1999). It is well known that the accumulation of PUFA potentiates the susceptibility to peroxidation, forming hydroperoxide and other degradation products that are deleterious to cells (Hu et al., 1989; Koh, 1997). PUFA that is taken into the body is primarily delivered to the liver cells (Nilsson et al., 1992); therefore, the liver is one of the principal targets of PUFA peroxidative effects.

All organisms respond to oxidative stress by inducing a variety of defense systems (Yu, 1994; Cho et al., 2000; Rahman et al., 2002). The role of antioxidants and the antioxidant defense system, such as superoxide dismutase, catalase, and glutathione peroxidase (GPx) to protect against oxidative insults, has been well characterized. Vitamin $\mathrm{E}$ is the most important lipid-soluble chain breaking antioxidant in tissues, red cells, and plasma (Burton and Traber, 1990). The vitamin may protect cellular components against peroxidative damage via the free radical-scavenging mechanism or as a constituent of the membrane (Chow, 1991). If primary or secondary lipid peroxidation products are involved in lipogenic enzyme suppression, it might be expected that the 
Table 1. Composition of experimental diets ${ }^{\mathrm{a}}$

\begin{tabular}{|c|c|}
\hline Ingredient & Fat-free basal diet \\
\hline & $g / 100 \mathrm{~g}$ \\
\hline Corn starch & 34.85 \\
\hline Sucrose & 34.85 \\
\hline Casein (vitamin-free) & 20.0 \\
\hline$\alpha$-cellulose & 5.0 \\
\hline Mineral mixture ${ }^{b}$ & 4.0 \\
\hline Vitamin mixture & 1.0 \\
\hline DL-methionine & 0.3 \\
\hline
\end{tabular}

${ }^{a}$ Experimental diets were prepared by mixing fat-free basal diet with $10 \mathrm{~g}$ each of corn oil (CO), beef tallow (BT), perilla oil (PO), fish oil (FO), and $1 \mathrm{~g}$ corn oil (1C) to $100 \mathrm{~g}$. $\alpha$-Tocopherol was supplemented in perilla oil $(0.015 \%$, w/w oil $)$ and fish oil $(0.019 \%$, w/w oil $)$.

${ }^{\mathrm{b}}$ AIN-76 Mineral mixture (ICN Biochemicals, Cleveland, USA), Provided (g/kg mixture): $\mathrm{CaHPO}_{4} 500 \mathrm{~g}, \mathrm{NaCl} 74 \mathrm{~g}, \mathrm{~K}_{2} \mathrm{SO}_{4} 52 \mathrm{~g}$, Potassium citrate monohydrate $220 \mathrm{~g}, \mathrm{MgO} 24 \mathrm{~g}$, Manganese carbonate $(42-48 \% \mathrm{Mn}) 3.5 \mathrm{~g}$, Ferric citrate $(16-17 \% \mathrm{Fe}) 6.0 \mathrm{~g}$, Zinc carbonate $(70 \% \mathrm{ZnO}) 1.6 \mathrm{~g}$, Cupric carbonate $(53-55 \% \mathrm{Cu})$ $0.3 \mathrm{~g}, \mathrm{KIO}_{3} 0.01 \mathrm{~g}$, Chromium potassium sulfate $0.55 \mathrm{~g}$, $\mathrm{Na}_{2} \mathrm{SeO}_{3} \cdot 5 \mathrm{H}_{2} \mathrm{O} 0.01 \mathrm{~g}$, Sucrose finely powdered $118.0 \mathrm{~g}$.

${ }^{\mathrm{A}} \mathrm{AIN}-76$ fortified vitamin mixture (ICN Biochemicals), Provided: Vit.A Acetate $(500,000 \mathrm{IU} / \mathrm{g}) 1.8 \mathrm{~g}$, Vit.D2 (850,000 IU/g) $0.125 \mathrm{~g}$, DL- $\alpha$-tocopherol (250 IU/g) $22.0 \mathrm{~g}$, Ascorbic acid $45.0 \mathrm{~g}$, Inositol $5.9 \mathrm{~g}$, Choline chloride $75.0 \mathrm{~g}$, Menadione $2.25 \mathrm{~g}$, $\gamma$-Aminobenzoic acid $5.0 \mathrm{~g}$, Niacin $4.25 \mathrm{~g}$, Riboflavin $1.0 \mathrm{~g}$, Pyridoxine hydrochloride $1.0 \mathrm{~g}$, Calcium pantothenate $3.0 \mathrm{~g}$, Biotin $0.02 \mathrm{~g}$, Folic acid $0.09 \mathrm{~g}$, Vit. $\mathrm{B}_{12} 0.00135 \mathrm{~g}$ and Dextrose to $1 \mathrm{~kg}$.

effect of PUFA would be modified by the antioxidant status of the body. In this respect, feeding diets that are enriched with antioxidants could reduce the capability of dietary PUFA for lipogenic enzyme suppression. To verify this hypothesis, we investigated the effect of dietary polyunsaturated fats, supplemented with vitamin E, on the activity and gene expression of hepatic FAS in rats. The relationship to the lipid peroxidation product and glutathione-dependent enzyme activities was also examined.

\section{Materials and Methods}

Animals and diets Weaning male Sprague-Dawley rats, supplied by the Laboratory Animal Care Facility of the Seoul National University (Seoul, Korea), were maintained under standard conditions $\left(23 \pm 2^{\circ} \mathrm{C}\right.$ temperature, $55 \pm 5 \%$ humidity, $12 \mathrm{~h}$ lightdark-cycle). The rats were individually caged with free access to water during the entire experimental period, and fed one of five experimental diets for $4 \mathrm{wk}$. In order to facilitate control of the dietary intake, all of the animals were adapted to a meal-eating regimen in which one meal allowed access to food for a $3 \mathrm{~h}$ period (0900-1200 h). Experimental diets were prepared by mixing a fatfree basal diet with $10 \%(10 \mathrm{~g} / 100 \mathrm{~g}$ diet $)$ each of corn oil, beef tallow, perilla oil, fish oil, and $1 \%(1 \mathrm{~g} / 100 \mathrm{~g}$ diet $)$ corn oil to
Table 2. Fatty acid composition of dietary fats ${ }^{\mathrm{a}}$

\begin{tabular}{lcccc}
\hline \multirow{2}{*}{ Fatty acids } & \multicolumn{4}{c}{ Dietary fat } \\
\cline { 2 - 5 } & Beef tallow & Corn oil & Perilla oil & Fish oil \\
\hline C14:0 & 3.96 & - & - & 3.59 \\
C15:0 & - & - & - & 1.36 \\
C16:0 & 28.36 & 11.85 & 6.80 & 25.66 \\
C16:1 & 2.79 & - & - & 5.50 \\
C18:0 & 20.87 & - & 2.07 & 6.65 \\
C18:1 & 44.02 & 28.94 & 15.23 & 13.83 \\
C18:2(n-6) & - & 57.29 & 13.67 & 1.62 \\
C18:3(n-3) & - & 0.93 & 61.49 & 1.08 \\
C20:0 & - & 0.54 & - & - \\
C20:1 & - & 0.45 & 0.48 & 1.52 \\
C20:2(n-6) & - & - & 0.25 & - \\
C20:5(n-3) & - & - & - & 6.47 \\
C22:6(n-3) & - & - & - & 32.72 \\
${ }^{\mathrm{D}} \Sigma$ SFA & 53.19 & 12.39 & 8.87 & 37.25 \\
$\Sigma$ n-6 & - & 57.29 & 13.92 & 1.62 \\
$\Sigma$ n-3 & - & 0.93 & 61.49 & 40.27 \\
\hline
\end{tabular}

${ }^{\text {a } V a l u e s ~ a r e ~ e x p r e s s e d ~ a s ~ p e r c e n t a g e ~ o f ~ t o t a l ~ f a t t y ~ a c i d s . ~}$

${ }^{b} \Sigma$ SFA, sum of saturated fatty acids;

$\Sigma \mathrm{n}-6$, sum of $\mathrm{n}-6$ polyunsaturated fatty acids

$\Sigma$ n-3, sum of n-3 polyunsaturated fatty acids.

provide minimal essential fatty acids as a control (Table 1). The amount of the fat-free basal diet was kept constant by matching the intakes of each day.

The fatty acid compositions of the dietary fats are shown in Table 2. To prevent autoxidation, $\alpha$-tocopherol was supplemented in perilla oil $(0.015 \%)$ and fish oil $(0.019 \%)$, based on the peroxidizability index (Witting, 1974). In addition, meals were offered daily, and diets were stored in the freezer and replenished with $\mathrm{N}_{2}$ gas to minimize the peroxidation of lipids.

Sample preparation The animals were sacrificed by decapitation at 90-120 min after completion of the final meal. An aliquot of each liver was quickly removed and snap frozen in liquid $\mathrm{N}_{2}$ and kept at $-70^{\circ} \mathrm{C}$ for a mRNA assay. About $5 \mathrm{~g}$ of liver was homogenized in 5 volume of an ice cold homogenizing-buffer solution $(154 \mathrm{mM} \mathrm{KCl}$, $1 \mathrm{mM}$ EDTA, $50 \mathrm{mM}$ Tris-HCl, $\mathrm{pH} \mathrm{7.4)}$ and centrifuged at $10,000 \times g$ for $20 \mathrm{~min}$, followed by recentrifugation of the supernatant at $105,000 \times g$ for $60 \mathrm{~min}$. The supernatant was considered the cytosol, and the pellet the microsome. The microsomal pellet was resuspended in a cold storage buffer (homogenizing buffer/glycerol, $80: 20$ ). The entire fractionation procedure was conducted at $4^{\circ} \mathrm{C}$.

Enzyme assays All of the enzymatic activities were assayed using hepatic cytosolic fraction. FAS were determined from the rate of malonyl-CoA dependent NADPH oxidation by the method of Linn (1981). The activities of glutathione peroxidase, and glutathione reductase (GR), glutathione S-transferase (GST) were measured according to the method of Tappel (1978), Carlberg and Mannervick (1985), and Habig et al. (1974), respectively. The 
protein concentration was measured by the method of Scopes (1996), modified Lowry method (1951).

Measurement of lipid peroxide content Lipid peroxidation in the hepatic microsomal fraction was determined by the production of thiobarbituric acid reactive substances (TBARS), according to the method of Buege and Aust (1978). Malondialdehyde was identified as the product of lipid peroxidation that reacted with thiobarbituric acid. The absorbance was determined at $535 \mathrm{~nm}$.

\section{Isolation of total RNA and Northern-blot hybridization of FAS}

Total RNA was extracted from the liver by the acid guanidinium thiocyanate-phenol-chloroform (AGPC) method (Chomczynski and Sacchi, 1987). The nucleic acid concentration was estimated spectrophotometrically by absorption at $260 \mathrm{~nm}$. A Northern blot analysis was performed, as described by Sambrook et al. (1989). The pBluescript-KS plasmid that contained the cDNA insert for rat FAS was a gift from Dr. Steven Clarke (University of Texas). The cDNA probes for FAS and glyceraldehyde phosphate dehydrogenase (GAPDH) were radiolabeled with $\left[\alpha-{ }^{32} \mathrm{P}\right]-\mathrm{dCTP}$ using a random primer-labeling kit (Promega, Madison, USA). Quantification of the Northern blots was achieved by a scanning microdensitometer (Perkin Elmer, Shelton, USA). Relative FAS mRNA levels were normalized to their respective GAPDH signals by quantitative densitometric scanning of the autoradiograms.

Statistical analysis All statistical analyses were carried out using ANOVA and Duncans multiple range test, $p$ value of $<0.05$ was selected as a limit of the statistical significance. The statistical program used was the SAS package (Cary, USA).

\section{Results and Discussion}

There were no significant differences in the diet intakes, final body weight, or weight increase rate among the $10 \%$ fat groups. Diet intakes were the same within a group because the rats were individually housed and adapted to a $3 \mathrm{~h}$ feeding regimen. Experimental groups that were fed $10 \%$ fat consumed the same amount of calories, carbohydrates, and other nutrients. Therefore, all of the results can be considered as the sole effect of the different dietary fats.

Numerous studies have shown that PUFA reduced the plasma triglyceride level in human and experimental animals (Williams, 1996; Yeo et al., 2000). Suppression of lipogenic enzymes has been suggested as a crucial factor of the hypotriglyceridemic effect (Clarke et al., 1990; Seboková et al., 1996). Our previous study confirmed that n-3 PUFA sources, such as fish and perilla oils, were effective in reducing the plasma and hepatic triglyceride levels (Kim and Choi, 2001). We reported that the hypolipidemic effect was related to the increase of eicosapentaenoic acid (EPA) and docosahexaenoic acid (DHA) contents in the hepatic membrane. However, without adequate levels of the antioxidants, the accumulation of PUFA increases susceptibility to lipid peroxidation. Our major concern is

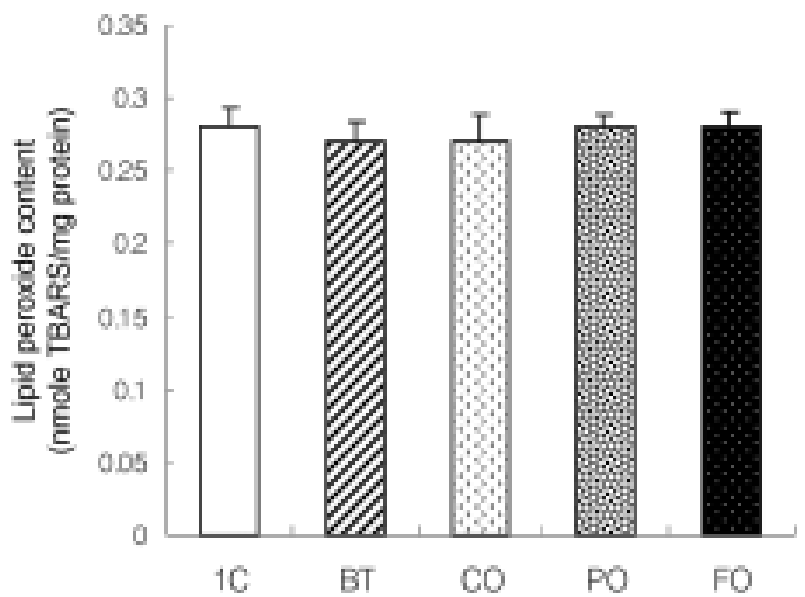

Fig. 1. Effect of dietary fats on hepatic thiobarbituric acid reactive substance (TBARS) content. Rats were fed each of the experimental diets for $4 \mathrm{wk}$ by a $3 \mathrm{~h}$ feeding protocol. 1C, $1 \%$ corn oil diet; BT, $10 \%$ beef tallow diet; CO, $10 \%$ corn oil diet; PO, $10 \%$ perilla oil diet; FO, $10 \%$ fish oil diet. Values are mean \pm SE of 8-9 rats. All of the groups were not significantly different at $\mathrm{p}<0.05$ by Duncans multiple range test.

whether the peroxidative damage, due to the increased PUFA, is involved in the suppression of lipogenic enzyme.

Concentrations of hepatic TBARS, as an estimate of lipid peroxidation, are shown in Fig. 1. There were no significant differences among the dietary groups. The PUFA-rich diets did not induce more lipid peroxidation than the saturated-fat and low-fat diets. This is contrary to previous reports that the dietary intake of n-3 PUFA increased peroxidative damage in the liver (Labbé et al., 1991; Song et al., 2000), but consistent with the result of Ando et al. (2000). In contrast to the higher doses and long-term treatments, $5 \%(\mathrm{w} / \mathrm{w})$ fish oil feeding for $6 \mathrm{wk}$ did not significantly induce lipid peroxidation. Thus, the moderate fat level in our study $(10 \% \mathrm{w} / \mathrm{w})$ may be a possible factor for the insignificant differences of peroxidation. Therefore, the susceptibility to peroxidation depends on the dose and duration of the dietary supplement of PUFA (Pazzola et al., 1996). In addition, a number of factors (including iron, vitamin E, and antioxidant defense systems) affect the extent of oxidative damage (Meydani et al., 1987; Wu et al., 1990; Javouhey-Donzel et al., 1993).

The activities of glutathione-dependent detoxifying enzymes were affected by the dietary fats. GPx functions as a protection enzyme against peroxidative damage by catalyzing the elimination of peroxides (Burk et al., 1980). The activity was increased in rats that were fed fish and perilla oil diets, n3 PUFA sources (Fig. 2). Dietary intake of n-3 PUFA sources resulted in a marked increase of EPA and DHA into the hepatic membrane (Kim and Choi, 2001), which can be associated with susceptibility to oxidative threats. However, these fatty acid changes have been reported to stimulate the activity and mRNA expression of some antioxidant enzymes (such as catalase, GPx, and superoxide dismutase) when 


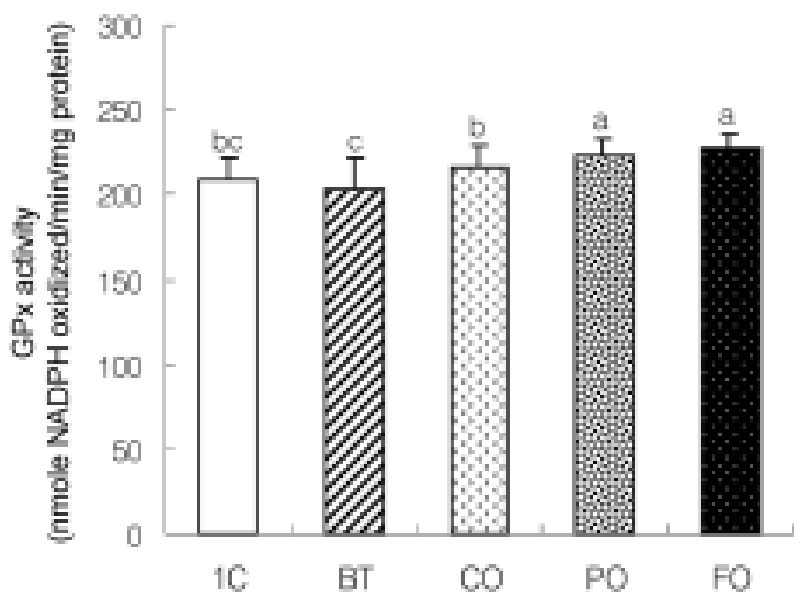

Fig. 2. Effect of dietary fats on glutathione-peroxidase (GPx) activity. Rats were fed each of the experimental diets for $4 \mathrm{wk}$ by a $3 \mathrm{~h}$ feeding protocol. $1 \mathrm{C}, 1 \%$ corn oil diet; BT, $10 \%$ beef tallow diet; $\mathrm{CO}, 10 \%$ corn oil diet; PO, $10 \%$ perilla oil diet; FO, $10 \%$ fish oil diet. Values are mean \pm SE of 8-9 rats, and means with the same subscripts were not significantly different at $\mathrm{p}<0.05$ by Duncans multiple range test.

Table 3. Effect of dietary fats on the activities of glutathione Stransferase (GST) and glutathione reductase (GR)

\begin{tabular}{ccc}
\hline Group & GST & GR \\
\cline { 2 - 3 } & $\begin{array}{c}\text { (nmole CDNB conjugated } \\
\text { /min/mg protein) }\end{array}$ & $\begin{array}{c}\text { (nmole NADPH oxidized } \\
/ \text { min/mg protein) }\end{array}$ \\
\hline 1C & $473.51 \pm 74.63^{\text {bc }}$ & $64.65 \pm 4.50^{\text {bc }}$ \\
BT & $394.07 \pm 33.62^{\mathrm{c}}$ & $62.54 \pm 6.51^{\mathrm{c}}$ \\
CO & $532.93 \pm 99.47^{\mathrm{b}}$ & $69.92 \pm 6.68^{\mathrm{b}}$ \\
PO & $534.00 \pm 109.96^{\mathrm{b}}$ & $68.72 \pm 6.43^{\mathrm{b}}$ \\
FO & $645.64 \pm 103.81^{\mathrm{a}}$ & $76.57 \pm 5.92^{\mathrm{a}}$ \\
\hline
\end{tabular}

Rats were fed each of the experimental diets for 4 wk by a $3 \mathrm{~h}$ feeding protocol. 1C, $1 \%$ corn oil diet; BT, $10 \%$ beef tallow diet; CO, $10 \%$ corn oil diet; PO, $10 \%$ perilla oil diet; FO, 10\% fish oil diet. Values are mean \pm SE of 8-9 rats, and the means with the same subscripts were not significantly different at $p<0.05$ by Duncans multiple range test.

compared to the n-6 PUFA rich diets (Venkatraman et al., 1994; Ruiz-Gutiérrez et al., 1999). The activities of GPx and GST, one isozyme of which also has GPx activity, are directly related to the cellular radical-scavenging capacity. In addition, the concomitant activity change of GR regulates the detoxifying capability by modulating the NADPH-dependent glutathione redox cycling. The activities of GR and GST were significantly elevated by the dietary PUFA sources, especially by fish oil, compared with beef tallow (Table 3). Thus, the concurrent increase in the activities of GPx and GR in fish oilfed rats would speed up the redox cycling. Moreover, the increase of GST activity would strengthen the cellular detoxifying potential.

It is well known that the level of vitamin $\mathrm{E}$, the most

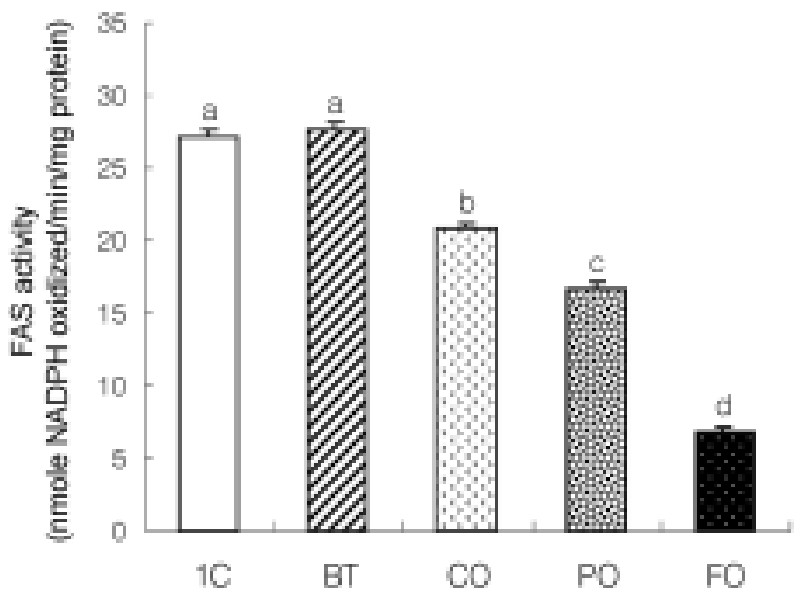

Fig. 3. Effect of dietary fats on fatty acid synthase (FAS) activity. Rats were fed each of the experimental diets for 4 wk by a $3 \mathrm{~h}$ feeding protocol. 1C, 1\%corn oil diet; BT, 10\% beef tallow diet; CO, $10 \%$ corn oil diet; PO, $10 \%$ perilla oil diet; FO, $10 \%$ fish oil diet. Values are mean \pm SE of 8-9 rats, and means with the same subscripts were not significantly different at $\mathrm{p}<0.05$ by Duncans multiple range test.

important antioxidant in the membrane, is decreased by the ingestion of PUFA, and can be recovered by vitamin E supplementation (Cho and Choi, 1994; Ibrahim et al., 1997). Stimulated antioxidant enzymes against free radical generation form the primary intracellular defense, and vitamin $E$ acts as a secondary defense that terminates the radical chain reaction once it is initiated. Recently, moderate vitamin E intake was reported to induce better status of antioxidants, such as glutathione, superoxide dismutase, GPx, and catalase, when compared with excess vitamin E intake (Eder et al., 2002). Thus, vitamin E seems to play a key protective role by affecting the antioxidant status, in addition to terminating the chain reaction. Since there was no difference in the TBARS levels in our study, this indicates that the susceptibility of PUFA to lipid peroxidation can be overcome by the minimum supplementation of vitamin $\mathrm{E}$ under the medium level of fat intake.

The cytosolic activity of FAS, the overall rate-limiting enzyme for fatty acid synthesis, is affected by dietary fats (Fig. 3). FAS activity of the beef tallow group was the highest when compared to that of the $1 \%$ corn oil diet group, but the activities were reduced in the polyunsaturated fat-fed groups. Among the polyunsaturated-fat groups, the reduction in FAS activity was the greatest in the rats that were fed fish oil. Perilla oil was more effective than corn oil in reducing the activity. The differences among each of the three groups were statistically significant. Considering the absence of reducing FAS activity in rats that were fed beef tallow that was rich in saturated fatty acids and oleic acid (Table 2, Fig. 3), the suppressive effect was absolutely due to the specific action of PUFA. The inhibitory potency of PUFA seems to vary, depending upon the degree of unsaturation and chain length, 

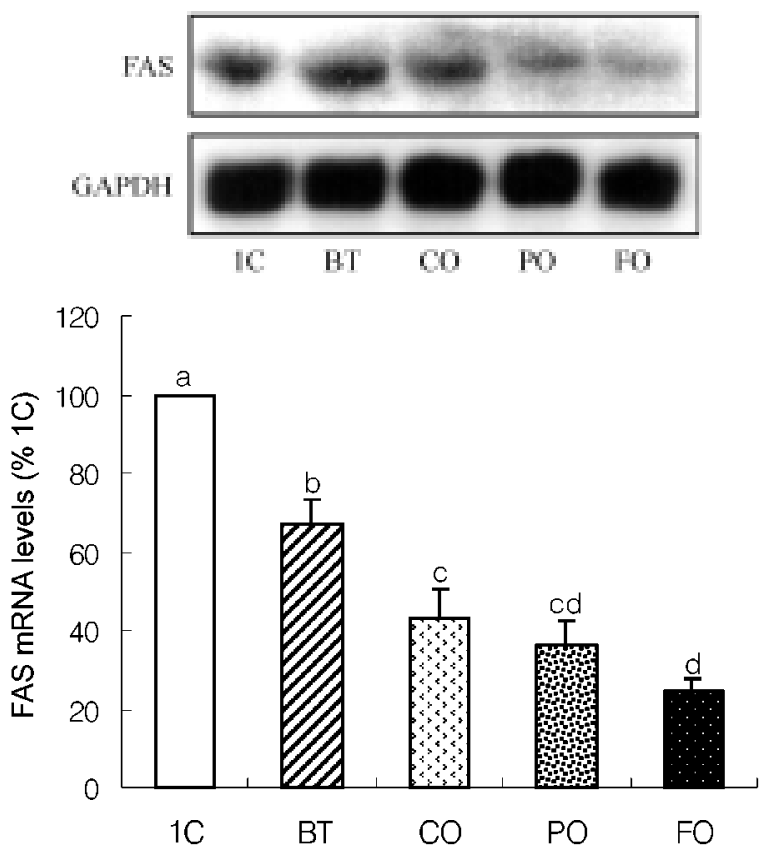

Fig. 4. Northern blot analysis of fatty acid synthase (FAS) mRNA in rat liver. Rats were fed each of the experimental diets for $4 \mathrm{wk}$ by a $3 \mathrm{~h}$ feeding protocol. $1 \mathrm{C}, 1 \%$ corn oil diet; BT, $10 \%$ beef tallow diet; CO, $10 \%$ corn oil diet; PO, $10 \%$ perilla oil diet; FO, $10 \%$ fish oil diet. RNA samples $(20 \mu \mathrm{g})$ were denatured and separated on a $1.3 \%$ agarose gel that contained formaldehyde, then transferred to a nylon membrane and fixed with UV crosslinking. FAS and GAPDH mRNA levels were analyzed by hybridization with radiolabeled cDNA probes. Relative FAS mRNA levels were normalized to their respective GAPDH levels, and are presented as a percentage of the $1 \mathrm{C}$ group (mean $\pm S E, n=4$ ). Means with the same subscripts were not significantly different at $\mathrm{p}<0.05$ by Duncans multiple range test.

as shown in other studies (Toussant et al., 1981; Clarke et al., 1990). As repeatedly observed in previous studies (Blake and Clarke, 1990; Clarke and Abraham, 1992), it is obvious that fish oil that is rich in EPA and DHA (Table 2) effectively suppressed the hepatic activity of the lipogenic enzyme. Polyenoic long-chain n-3 PUFA (DHA, EPA) are the most potent fatty acids in reducing hepatic lipogenic enzyme activities and fatty acid synthesis (Blake and Clarke, 1990; Clarke and Jump, 1993). Although there were some studies that failed to show any significant differences between LA and $\alpha$-LNA (Ide et al., 1996), our study showed that FAS activity in rats that were fed perilla oil rich in $\alpha$-LNA was lower than that of rats fed corn oil rich in LA. This is consistent with the results of several studies (Clarke and Jump, 1993; Ikeda et al., 1998). We reported that dietary perilla oil resulted in the high content of EPA and DHA in the hepatic membrane with a low content of arachidonic acid (Kim and Choi, 2001). This result was probably due to the suppressed biosynthesis of arachidonic acid from LA by the presence of $\alpha$-LNA in perilla oil, because LA and $\alpha$-LNA compete for $\Delta^{6}$ - desaturase to further elongate and desaturate. Even though the products of $\Delta^{6}$ - desaturase are two to four times more potent suppressors than LA, $\alpha$-LNA itself (Clarke and Jump, 1994; Jump et al., 1996), the resulting high concentration of EPA and DHA in perilla oil-fed group could suppress FAS activity more effectively than arachidonic acid in the corn oil-fed group. Therefore, feeding perilla and fish oil diets that are rich in n-3 PUFA ( $\alpha$-LNA, EPA, DHA) resulted in lowering the FAS activity when compared to feeding a LA rich corn oil diet.

Figure 4 shows the relative contents of FAS mRNA as an estimate of gene expression. The mRNA content was reduced in the rats that were fed the $10 \%$ fat diets, particularly polyunsaturated fats, compared to the $1 \%$ corn oil diet. Among the polyunsaturated fats, fish oil supplementation resulted in the lowest FAS mRNA content, which was reduced to $25 \%$ of the $1 \%$ corn oil group. The FAS mRNA content of perilla oil was the intermediate level between fish oil and corn oil, even though it was insignificant. But the difference between fish oil and corn oil was significant. The inhibitory capability of polyunsaturated fat, especially fish oil, on the FAS mRNA expression was consistent with other reports (Clarke et al., 1990; Jump et al., 1994). In our study, a positive correlation between the FAS specific activity and relative amounts of FAS mRNA $(r=0.757, p<0.0005)$ was found, which suggests that regulation is primarily done at the pretranslational level. Although the inhibitory effect of PUFA on the lipogenic gene has been suggested to be a direct transcriptional effect of PUFA, a recent study that used a primary hepatic monolayer culture indicated that PUFA require oxidative modification to exert their suppressive effect on the lipogenic gene expression (Foretz et al., 1999). It is conceivable that hepatocytes in vivo are more effectively protected from the cytotoxic effects of peroxidation due to various defense mechanisms; therefore, it seems likely that peroxidation products do not accumulate the same as they do in the in vitro culture. However, very few studies have investigated the relationship between the lipogenic gene transcription and oxidative stress in vivo. In our study, the minimum amount of vitamin $\mathrm{E}$ was supplemented to the PUFA-rich diets in order to eliminate the peroxidative damage, due to the lowered antioxidant status. Even though the results of the TBARS content showed that the vitamin E level was sufficient to abolish the lipid peroxidation factor, the FAS mRNA content was reduced in the polyunsaturated fatfed groups, particularly in the fish oil-fed group. This result was supported by the study of Eder and Kirchgessner (1998). They reported that neither the endogenous nor exogenous lipid peroxidation products play a significant role in the suppression of lipogenic enzymes. Therefore, our result suggests that the inhibitory effect of PUFA on the lipogenic gene in vivo was due to the direct transcriptional effect of PUFA itself, not by peroxidative damage. However, studies on the FAS gene transcription in vitro are needed under various conditions to elucidate the cellular mechanism of the gene expression and defense response to oxidative stress and 
antioxidants.

In summary, we found that lipid peroxidation products can be minimized by vitamin E, and dietary PUFA in itself plays a key role in the suppression of the lipogenic enzyme.

\section{References}

Ando, K., Nagata, K., Yoshida, R., Kikugawa, K. and Suzuki, M. (2000) Effect of n-3 polyunsaturated fatty acid supplementation on lipid peroxidation of rat organs. Lipids 35, 401-407.

Blake, W. L. and Clarke, S. D. (1990) Suppression of rat hepatic fatty acid synthase and S14 gene transcription by dietary polyunsaturated fat. J. Nutr. 120, 1727-1729.

Buege, J. A. and Aust, S. D. (1978) Microsomal lipid peroxidation; in Methods in Enzymology, Sidney, F. and Lester, P. (eds.), vol 52, pp. 302-310, Academic Press, New York, USA.

Burk, R. F., Trumble, M. J. and Lawrence, R. A. (1980) Rat hepatic cytosolic glutathione-dependent enzyme protection against lipid peroxidation in the NADPH-microsomal lipid peroxidation system. Biochim. Biophy. Acta 619, 34-41.

Burton, G. W. and Traber, M. G. (1990) Vitamin E: antioxidant activity, biokinetics, and bioavailability. Ann. Rev. Nutr. 10, 357-382.

Carlberg, I. and Mannervick, B. (1985) Glutathione reductase; in Methods in Enzymology, Fleisher, S. and Packer, L. (eds.), vol 113, pp. 484-490, Academic Press, New York, USA.

Cho, S. H. and Choi, Y. S. (1994) Lipid peroxidation and antioxidant status is affected by dietary vitamin E levels when feeding fish oil. Lipids 29, 47-52.

Cho, Y., Park, E. and Lim, C. (2000) Catalase, glutathione Stransferase and thiotransferase respond differently to oxidative stress in Schizosaccharomyces pombe. J. Biochem. Mol. Biol. 33, 344-348.

Chomczynski, P. and Sacchi, N. (1987) Single step method of RNA isolation by acid guanidinium thiocyanate-phenolchloroform extraction. Anal. Biochem. 162, 156-159.

Chow, C. K. (1991) Vitamin E and oxidative stress. Free Radic. Biol. Med. 11, 215-232.

Clarke, B. A. and Clarke, S. D. (1982) Suppression of rat liver fatty acid synthesis by eicosa-5, 8,11,14-tetraynoic acid without a reduction in lipogenic enzyme. J. Nutr. 112, 1212-1219.

Clarke, S. D. and Abraham, S. (1992) Gene expression: nutrient control of pre- and posttranscriptional events. FASEB J. 6, 3146-3152.

Clarke, S. D. and Jump, D. B. (1993) Regulation of hepatic gene expression by polyunsaturated fats: A unique role for polyunsaturated fatty acids; in Nutrition and Gene Expression Berdanier, C. D. and Hargrove, J. L. (eds.), pp. 227-246, CRC press, Ann Arbor, USA.

Clarke, S. D. and Jump, D. B. (1994) Dietary polyunsaturated fatty acid regulation of gene transcription. Ann. Rev. Nutr. 14, 83-98.

Clarke, S. D., Armstrong, M. K. and Jump, D. B. (1990) Dietary polyunsaturated fats uniquely suppress rat liver fatty acid synthase and S14 mRNA content. J. Nutr. 120, 225-231.

Clarke, S. D., Romsos, D. R. and Leveille, G. A. (1977) Differential effects of dietary methyl esters of long-chain saturated and polyunsaturated fatty acids on rat liver and adipose tissue lipogenesis. J. Nutr. 107, 1170-1181.

Eder, K., Flader, D., Hirche, F. and Bransch, C. (2002) Excess dietary vitamin $\mathrm{E}$ lowers the activities of antioxidant enzymes in erythrocytes of rats fed salmon oil. J. Nutr. 132, 3400-3404.

Eder, K. and Kirchgessner, M. (1998) The effect of dietary vitamin E supply and a moderately oxidized oil on activities of hepatic lipogenic enzymes in rats. Lipids 33, 277-283.

Foretz, M., Foufelle, F. and Ferre, P. (1999) Polyunsaturated fatty acids inhibit fatty acid synthase and spot-14-protein gene expression in cultured rat hepatocytes by a peroxidative mechanism. Biochem. J. 341, 371-376.

Habig, W. H., Pabst, M. J. and Jakoby, W. B. (1974) Glutathione S-transferase J. Biol. Chem. 249, 7130-7139.

Hu, M. L., Frankep, E. N., Leibovitz, B. E. and Tappel, A. L. (1989) Effect of dietary lipids and vitamin $\mathrm{E}$ on in vitro lipid peroxidation in rat liver and kidney homogenates. J. Nutr. 118, 1574-1585.

Ibrahim, W., Lee, W. S., Yeh, C., Szabo, J., Bruckner, G. and Chow, C. K. (1997) Oxidative stress and antioxidant status in mouse liver: effect of dietary lipid, vitamin E and iron. J. Nutr. 127, 1401-1406.

Ide, T., Murata, M. and Sugano, M. (1996) Stimulation of the activities of hepatic fatty acid oxidation enzymes by dietary fat rich in $\alpha$-linolenic acid in rats. J. Lipid Res. 37, 448-463.

Ikeda, J., Cha, J. Y., Yanagita, T., Nakatani, N., Oogami, K., Imaizumi, K. and Yazawa, K. (1998) Effects of dietary alphalinolenic, eicosapentaenoic and docosahexaenoic acids on hepatic lipogenesis and beta-oxidation in rats. Biosci. Biotechnol. Biochem. 62, 675-680.

Javouhey-Donzel, A., Guenot, L., Maupiol, V., Rochette, L. and Rocquelin, G. (1993) Rat vitamin E status and heart lipid peroxidation: effect of dietary $\alpha$-linolenic acid and marine $n-3$ fatty acids. Lipids 28, 651-655.

Jump, D. B., Clarke, S. D., Thelen, A. and Liimatta, M. (1994) Coordinate regulation of glycolytic and lipogenic gene expression by polyunsaturated fatty acids. J. Lipid Res. 35, 1076-1084.

Jump, D. B., Clarke, S. D., Thelen, A., Liimatta, M., Ren, B. and Badin, M. (1996) Dietary polyunsaturated fatty acid regulation of gene transcription. Prog. Lipid Res. 35, 227-241.

Kim, H. and Choi, H. (2001) Dietary $\alpha$-linolenic acid lowers postprandial lipid levels with increase of eicosapentaenoic and docosahexaenoic acid contents in rat hepatic membrane. Lipids 36, 1331-1336.

Koh, Y. H., Yoon, S. J. and Park, J. W. (1997) Lipid peroxidation product-mediated DNA damage and mutagenicity. J. Biochem. Mol. Biol. 30, 188-193.

Labbé, M. R., Trick, K. D. and Beare-Rogers, J. L. (1991) Dietary (n-3) fatty acids affect rat heart, liver and aorta protective enzyme activities and lipid peroxidation. J. Nutr. 121, 13311340.

Linn, T. C. (1981) Purification and crystallization of rat liver fatty acid synthetase. Arch. Biochem. Biophys. 209, 613-619.

Lowry, O. H., Rosebrough, N. J., Farr, A. L. and Randall, R. T. (1951) Protein measurement with folin phenol reagent. J. Biol. Chem. 193, 265-275.

Meydani, S. N., Shapiro, A. C., Meydani, M., Macauley, J. B. and Blumberg, J. B. (1987) Effect of age and dietary fat (fish oil, corn and coconut oils) on tocopherol status of C57BL/6Nia 
mice. Lipids 22, 345-350

Mikkelson, L., Hansen, H. S., Grunnet, N. and Dich, J. (1993) Inhibition of fatty acid synthesis in rat hepatocytes by exogenous polyunsaturated fatty acids is caused by lipid peroxidation. Biochim. Biophys. Acta 1166, 99-104.

Nilsson, A., Hjelte, L. and Strandvik, B. (1992) Incorporation of dietary [14C]arachidonic acid and $[3 \mathrm{H}]$ eicosapentaenoic acid into tissue lipids during absorption of a fish oil emulsion. $J$. Lipid Res. 33, 1295-1305.

Pazzola, P., Sgarlata, E., Luberto, C., Piccioni, E., Anti, M., Marra, G., Armelao, F., Franceshelli, P. and Bartoli, G. M. (1996) n-3 fatty acids induce oxidative modification in human erythrocytes depending on dose and duration of dietary supplementation. Am. J. Clin. Nutr. 64, 297-304.

Rahman, S. M., Huda, M. N., Uddin, M. N. and Akhteruzzaman, S. (2002) Short-term administration of conjugated linoleic acid reduces liver triglyceride concentration and phosphatidate phosphohydrolase activity in OLETF rats. J. Biochem. Mol. Biol. 35, 494-497.

Ruiz-Gutiérrez, V., Pérez-Espinosa, A., Vázquez, C. M. and SantaMaria, C. (1999) Effect of dietary fats (fish, olive and higholeic acid sunflower oils) on lipid composition and antioxidant enzymes in rat liver. Br. J. Nutr. 82, 233-241.

Sambrook, J., Fitsch, E. F. and Maniatis, T. (1989) Analysis of RNA; in Molecular Cloning: A Laboratory Manual, 2nd ed., Cold Spring Harbor Laboratory Press, New York, USA.

Scopes, R. K. (1996) Protein concentration determination; in Protein methods, Bollag, D. M., Rozycki, M. D. and Edelstein, S. J. (eds.), pp. 56-58, Wiley-Liss, New York, USA.

Seboková, E., Klimeš, I., Gašperiková, P., Bohov, P., Langer, P., Lavau, M. and Clandinin, M. T. (1996) Regulation of gene expression for lipogenic enzymes in the liver and adipose tissue of hereditary hypertriglyceridemic, insulin-resistant rats: effect of dietary sucrose and marine fish oil. Biochim. Biophys. Acta 1303, 56-62.

Song, J. H., Fujimoto, K. and Miyazawa, T. (2000) Polyunsaturated (n-3) fatty acids susceptible to peroxidation are increased in plasma and tissue lipids of rats fed docosahexaenoic acid-containing oils. J. Nutr. 130, 3028-3033.

Tappel, A. I. (1978) Glutathione peroxidase and hydroperoxides; in Methods in Enzymology, Fleisher, S. and Packer, L. (eds.) vol. 52, pp. 506-513, Academic Press, New York, USA.

Toussant, M. J., Wilson, M. D. and Clarke, S. D. (1981) Coordinate suppression of liver acetyl-CoA carboxylase and fatty acid synthetase by polyunsaturated fat. J. Nutr. 111,146153.

Venkatraman, J. T., Chandrasekar, B., Kim, J. D. and Fernandes, G. (1994) Effect of n-3 and n-6 fatty acids on the activities and expression of hepatic antioxidant enzymes in autoimmuneprone NZB X NZW F1 mice. Lipids 29, 561-568.

Williams, C. M. (1996) Disposition of lipids in the postprandial state. Proc. Nutr. Soc. 55, 79-91.

Witting, L. A. (1974) Vitamin E-polyunsaturated lipid relationship in diet and tissues. Am. J. Clin. Nutr. 27, 952-959.

Wu, W. H., Meydani, M., Meydani, S. N, Burklund, P. M., Blumberg, J. B. and Munro, H. N. (1990) Effect of dietary iron overload on lipid peroxidation, prostaglandin synthesis and lymphocyte proliferation in young and old rats. J. Nutr. 120, 280-289.

Yeo, Y. K., Kim, J. S., Lee, J. R., Lee, J. Y., Chung, S. W., Kim, H. J., Horrocks, L. A. and Park, Y. S. (2000) Plasma phospholipids, including plasmalogens, after consumption of diets enriched in long-chain n-3 fatty acids. J. Biochem. Mol. Biol. 33, 499-505.

Yu, B. P. (1994) Cellular defenses against damage from reactive oxygen species. Physiol. Rev. 74, 139-162. 